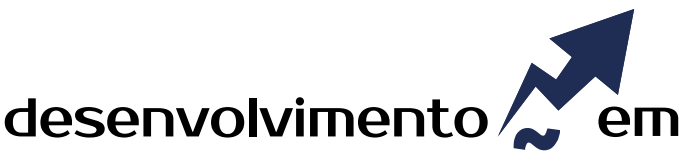 QUESTÃO
}

\section{Desenvolvimento Socioeconômico \\ e Cooperativismo de Crédito no Município de Concórdia-SC}

\author{
http://dx.doi.org/10.21527/2237-6453.2020.52.308-323
}

Recebido em: $15 / 4 / 2020$

Aceito em: 20/5/2020

\author{
Bruno Pilatti Rovani, ${ }^{1}$ Jairo Marchesan, ${ }^{2}$ \\ Fernando Maciel Ramos, ${ }^{3}$ Letícia Paludo Vargas ${ }^{4}$
}

\begin{abstract}
RESUMO
Diante da organização e da conjuntura política, social, e, principalmente, econômica mundial, o cooperativismo apresenta-se como uma das possibilidades para reduzir os processos excludentes do modo de produção capitalista. Assim, mostra-se, também, como possibilidade de inclusão social e econômica nos processos de produção, distribuição e consumo. O cooperativismo de crédito vem ocorrendo de forma crescente no Brasil, especialmente na Região Sul do país. A presente pesquisa foi desenvolvida no município de Concórdia-SC, com o objetivo de avaliar os avanços do cooperativismo de crédito no município e suas contribuições para o desenvolvimento socioeconômico. Para a coleta de dados utilizou-se a técnica de pesquisa de campo descritiva, com a aplicação de questionário nas cooperativas de crédito. Os resultados revelam que as contribuições das cooperativas de crédito para o desenvolvimento local estão centradas em quatro categorias, quais sejam: (i) ações sociais; (ii) formação de capital humano; (iii) empreendedorismo e (iv) finanças pessoais. Além disso, conclui-se que o sistema cooperativista de crédito está contribuindo significativamente na geração de trabalho, distribuição de renda, e, consequentemente, com o desenvolvimento local e regional.
\end{abstract}

Palavras-chave: Cooperativas. Desenvolvimento. Cooperação. Economia.

\section{SOCIO ECONOMIC DEVELOPMENT AND CREDIT COOPERATIVES IN CONCÓRDIA CITY}

\section{ABSTRACT}

Faced with the organization and the political, social, and economic world situation, the cooperativism is as one of the possibilities to reduce the exclusionary processes of the capitalist of production mode. It also presents like a possibility of social and economic inclusion in the processes of production, distribution and consumption. Credit cooperatives are present in Brazil, especially in the south region of the country. The research was carried out in Concórdia - SC city. The aims were of evaluating the progress of credit cooperatives in the city and their contributions to socioeconomic development. For data collection, the descriptive field research technique was used, with the application of a survey in credit unions. The results show that the contributions of credit unions to local development are centered on four categories, namely: (i) social actions; (ii) formation of human capital; (iii) entrepreneurship; (iv) personal finance. In addition, it is concluded that the cooperative credit system is contributing significantly to job creation, income distribution and, consequently, to local and regional development.

Keywords: Credit Unions. Development. Cooperative. Economy.

\footnotetext{
${ }^{1}$ Graduando em Ciências Contábeis pela Universidade do Contestado (UnC). http://lattes.cnpq.br/9607201778800094. https://orcid.org/0000-0002-8693-9427. brunoprovani@gmail.com

${ }^{2}$ Doutor em Geografia pela Universidade Federal de Santa Catarina (UFSC). Professor do Programa de Mestrado em Desenvolvimento Regional da Universidade do Contestado (UnC). http://lattes.cnpq.br/0110263539586001. jairo@unc.br

${ }^{3}$ Doutor em Ciências Contábeis pela Universidade do Vale do Rio dos Sinos (Unisinos). Professor da Universidade do Contestado (UnC). http://lattes.cnpq.br/1945276106615962.https://orcid.org/0000-0002-4222-1253.framos@unc.br

${ }^{4}$ Doutora em Extensão Rural pela Universidade Federal de Santa Maria (UFSM). Professora da Universidade do Contestado (UnC). http://lattes.cnpq.br/7734168457042680. https://orcid.org/0000-0002-9186-2508. letipvargas@gmail.com
} 
As cooperativas de crédito desempenham um relevante papel na economia de diferentes países, agindo como uma das principais fontes de crédito para pequenas e médias empresas e pessoas físicas (MCKILLOP et al., 2020). Diante da organização social, política e econômica mundial do modo de produção capitalista, o cooperativismo pode ser uma das possibilidades para promover a inclusão e distribuição de renda mais exequível e equitativa para pessoas físicas e também para as organizações (NOVKOVIC, 2008). Desta forma, diferentemente das demais instituições privadas de crédito, os tradicionais "bancos" que atuam no município de Concórdia-SC e na região do Alto Uruguai Catarinense, que prestam serviços, e, normalmente, levam seus bônus ou lucros para fora do município, da região e mesmo do país, as cooperativas de crédito podem reverter seus resultados e trazer benefícios, diretos e indiretos, para a localidade em que estão inseridas.

O cooperativismo de crédito destaca-se por algumas ações: presta contas nas assembleias aos associados, devolve os lucros, investe na formação técnica e humana do seu quadro de funcionários ou colaboradores, incentiva e divulga os princípios de cooperação, investe em ações sociais locais e regionais, entre outras ações. Consequentemente, promove o dinamismo da economia, contribui para a melhoria da qualidade de vida das pessoas, principalmente dos associados, e, consequentemente, com o desenvolvimento local e regional (RISSON, 2010).

O princípio da cooperação é inerente à sociedade humana, uma vez que as práticas de cooperação humana ocorrem desde as sociedades primitivas e, com maior ou menor intensidade, até a contemporaneidade. Cooperar, portanto, pode significar a superação das inseguranças, medos e fragilidades - características do individualismo - e potencializar valores coletivos de organização, solidariedade, respeito e segurança (MARCHESAN; BONETI; TOMPOROSKI, 2019).

A primeira cooperativa mundial foi fundada na cidade de Rochdale, na Inglaterra, no ano de 1844 (OCESC/SESCOOP/SC, 2018). Na época, 28 tecelões constituíram, portanto, a primeira cooperativa. Já no Brasil, a primeira cooperativa foi constituída no Estado de Minas Gerais, em 27 de outubro de 1889, denominada Sociedade Cooperativa Econômica dos Funcionários Públicos de Ouro Preto. Mais tarde, outras cooperativas expandiram-se para outros Estados (CANÇADO, 2014). Em 2 de dezembro de 1969 foi criada a Organização das Cooperativas do Brasil (OCB), esta afiliada à Aliança Cooperativista Internacional $(\mathrm{ACl})$ e ao Serviço Nacional de Aprendizagem do Cooperativismo (SESCOOP, 2017).

O cooperativismo cresce significativamente e se apresenta como uma das alternativas para a sociedade atual. Isto justifica o fato de que no ano de 2012 a Organização das Nações Unidas (ONU) reconheceu a força do setor e declarou como o Ano Internacional das Cooperativas. O Brasil possui aproximadamente 7 mil cooperativas. São mais de 50 milhões de brasileiros que, direta ou indiretamente, têm nas cooperativas uma fonte de trabalho e renda (ANUÁRIO..., 2019). Além disso, são mais de 900 cooperativas de crédito em todo o país. Entre os anos de 2014 e 2018 o número de cooperados cresceu 42\%. Em 594 munícipios as cooperativas de crédito são as únicas instituições financeiras que possuem sede ou posto de atendimento presentes (ANUÁRIO..., 2019). 
De igual modo, o cooperativismo no Estado de Santa Catarina é crescente e sólido em praticamente todos os setores e regiões (ZORDAN, 2016). Para o referido autor, um terço da população de Santa Catarina está diretamente vinculada ao cooperativismo. Dado o exposto, este artigo tem como objetivo avaliar os avanços do cooperativismo de crédito no município de Concórdia-SC, e apresenta as contribuições do setor para o desenvolvimento socioeconômico regional.

Para elucidar o objetivo deste estudo este artigo está estruturado em cinco seções, a primeira esta, em que são apresentados os aspectos introdutórios da investigação. Na sequência é apresentada a revisão teórica acerca do cooperativismo de crédito, com foco na exposição de estudos correlatos. Na terceira seção é apresentado o percurso metodológico adotado para o alcance do objetivo. Com os dados analisados, os achados são apresentados e discutidos na quarta seção, e por fim, na quinta seção são apresentadas as considerações finais.

\section{REFERENCIAL TEÓRICO: Cooperativismo de Crédito}

Os serviços prestados aos cooperados pelas cooperativas de crédito são semeIhantes aos utilizados pelas tradicionais agências de crédito, ou popularmente conhecidas como "bancos". Executam, portanto, praticamente todas as ações, entre as quais destacam-se, por exemplo, operar com cartões de crédito, contas correntes, fundos de investimento, seguros, aplicações, diversos tipos de empréstimos, entre outros (VILELA; NAGANO; MERLO, 2008). Nas cooperativas de crédito a eficiência fica associada a quanto a mais será agregado aos cooperados, maximizando resultados, materializados em operações de créditos e benefícios líquidos. Em contrapartida, quanto aos recursos empregados para sua obtenção a eficiência pode ser considerada uma medida da capacidade que agentes ou mecanismos têm de melhor para atingir seus objetivos, de produzir efeitos esperados, em virtude dos recursos disponíveis (FERREIRA; GONÇALVES; BRAGA, 2007).

Inseridas no meio econômico financeiro do país desde 1902, as cooperativas de crédito apresentam-se importantes sob o ponto de vista econômico e social, afinal, promovem a aplicação de recursos privados e públicos, assumindo compromissos sociais, políticos e, principalmente, econômicos em favor da comunidade na qual estão inseridas e atuam (PORTO; FERREIRA, 2014). Segundo o Anuário do Cooperativismo Brasileiro (2019), no final do ano de 2018 havia 10.548.288 cooperados. Do ano de 2017 para 2018 houve um incremento de $18,6 \%$ de novos cooperados no segmento de crédito. De 2018 para 2019 registrou-se um aumento de 9,4\% em relação ao mesmo período do ano anterior. Conforme o mesmo documento, a maior parcela (55\%) dos cooperados está situada na Região Sul do país, seguida pelas Regiões Sudeste (28\%), Centro-Oeste (11\%), Nordeste (4\%) e Norte (2\%). Tais dados demonstram o crescimento expressivo desse setor, o qual pode influenciar positivamente também para a economia brasileira, para as regiões e especialmente para os municípios em que atuam.

As premissas cooperativistas podem ser facilmente classificadas nos seguintes aspectos (BRESSAN et al., 2010): suas intenções em relação ao mercado ou à sociedade são facilmente identificadas, tendo suas identidades reveladas por meio de Estatutos Sociais, que são expostos a todo e qualquer público que tenha interesse em observar 
quais premissas e diretrizes sustentam essa sociedade cooperativista; utilizam-se dos esforços oferecidos de maneira mútua e voluntária pelos seus cooperados, como forma de se sustentar e de operar com baixos custos de manutenção; buscam resultados positivos ao final do seu exercício anual. As cooperativas socializam as sobras com seus associados ou cooperados, além dos serviços prestados em sua região de atuação que auxiliam no desenvolvimento econômico e social. Assim entendido, as cooperativas atuam com princípios, entre os quais a transparência com seus associados, explanando os saldos financeiros obtidos no período de atuação por meio de Assembleias Ordinárias.

As cooperativas financeiras são moldadas a partir de quatro princípios gerais, sendo eles a autoajuda, que decorre do objetivo econômico e social comum que leva à união de seus cooperados/associados; identidade, uma vez que na sua maioria possuem um foco de atuação em prol de uma comunidade, grupo de organizações e indivíduos; democracia, pois cada um dos seus cooperados possui o direito a voto, independentemente da quantidade das cotas de capital que detenha, o que reduz o controle da entidade por um indivíduo ou um grupo; e a cooperação, que permite a realização de alianças com outras instituições para fornecimento de melhores serviços financeiros à comunidade atendida (MCKILLOP et al., 2020). É em virtude de seus próprios princípios de atuação e valores que as cooperativas de crédito possuem vantagens únicas para promoção da estabilidade econômica, social, trabalhista e democrática, sendo esses os pilares fundamentais que caracterizam a capacidade dessas entidades na promoção do desenvolvimento local e regional onde estão inseridas (BRETOS; MARCUELLO, 2016).

Cooperativas de crédito mais eficientes desempenham melhor seu papel socioeconômico, o que resulta na ampliação de três importantes fatores. Primeiramente, ocorre a promoção da desintermediação financeira, que se torna o diferencial entre as taxas de captação e empréstimos, realizados aos cooperados, gerando mais oportunidades para a circulação de recursos, e, consequentemente, o desenvolvimento local, uma vez que depositantes e tomadores de empréstimos normalmente pertencem à mesma localidade (FERREIRA; GONÇALVES; BRAGA, 2007).

É proposto pelas cooperativas promoverem a solução simples e prática para conflitos existentes entre as mencionadas características: a do cidadão, que enfatiza o bem público e a responsabilidade social, e a do ator econômico, interessado na produção eficiente de bens ou serviços (ANTONIALLI, 2011). O cooperativismo ressalta a importância da cooperação, do preço justo e da distribuição mais igualitária dos resultados, tornando-se, por isso, importante fator social no processo de desenvolvimento socioeconômico. Não se pode, no entanto, descrever as cooperativas como associações beneficentes ou de fins apenas públicos. Existem objetivos econômicos de produção e de coordenação do setor de trabalho. Assim sendo, quanto maior a profissionalização e a capacitação da gestão das cooperativas, melhores resultados serão alcançados, o que não significa abrir mão de seus princípios (MENEZES; LAJUS, 2015).

As cooperativas podem contribuir de forma eficiente para esse fim, pela própria característica, que é a distribuição dos resultados, na qual não existe lucro (expropriação, aceita e regulada pelas forças de mercado, da mais-valia, ou seja, do trabalho excedente que fica com o dono do capital), mas sim a sobra (devolução legal da mais-valia que retorna à origem, retorna a quem gerou, por via do sistema cooperativista) (MENEZES; LAJUS, 2015). 
Samian et al. (2017) argumentam que a influência das cooperativas não está relacionada apenas às estruturas institucionais próprias, mas também às instituições econômicas que podem criar conexões profundas e impactar nas relações humanas e sociais. Estudos no âmbito nacional e internacional já buscaram investigar o impacto das cooperativas de crédito na economia, no desenvolvimento regional e no desenvolvimento de setores. Jacques e Gonçalves (2016) destacam que essas organizações são promotoras do desenvolvimento local. Os autores encontraram que a presença das cooperativas de crédito impacta em média em $\mathrm{R} \$ 1.825,00$ no PIB per capita de um município. Ao avaliar o impacto dos bancos cooperativos na Itália, Caporale et al. (2016) concluíram que essas instituições possuem um efeito não linear no crescimento da economia local em que estão inseridas, sendo coerente com os estudos empíricos acerca da relação entre finanças e crescimento econômico. Para avaliar o impacto das cooperativas de crédito no crescimento econômico local, Coccorese e Shaffer (2018) identificaram que essas instituições desenvolvem um importante papel no desempenho econômico do local em que se encontram inseridas, por meio do aumento da taxa de crescimento de empresas e, consequentemente, empregos e renda. Desse modo, os autores defendem que a presença dessas instituições de forma mais difundida pode ser benéfica para áreas com baixas taxas de crescimento. Nan, Gao e Zhou (2019) identificaram que a concessão de financiamento e empréstimos por cooperativas de crédito rural na China aumenta de forma significativa a produção agrícola, desse modo contribuindo para o desenvolvimento regional das regiões em que estão inseridas, e consequentemente do setor.

Visando a entender a contribuição das cooperativas de crédito para o desenvolvimento da agricultura familiar, Fernandes et al. (2018) realizaram um estudo de caso em relação à Sulcredi Ouro. Como principal colaboração, os autores concluíram que as cooperativas de crédito são entes relevantes para o desenvolvimento sustentável da agricultura familiar da região, atuando como um agente financeiro na concessão de créditos especializados. Wildner, Oliveira e Martinelli Junior (2018), avaliando as ações de cooperativas agrícolas, encontraram que elas são importantes agentes econômicos para o desenvolvimento regional e crescimento da cadeia produtiva. Desse modo, percebe-se que, independentemente do ramo de atuação da cooperativa, os estudos concluem que essas organizações são instituições que podem colaborar para o ambiente no qual estão inseridas.

Na seção seguinte são apresentados os procedimentos metodológicos adotados para a realização do estudo e a apresentação de informações que caracterizam o município em que fora realizado o estudo.

\section{PROCEDIMENTOS METODOLÓGICOS}

\section{Coleta e Análise de Dados}

Os estudos no âmbito das Ciências Sociais Aplicadas podem ser classificados quanto ao seu objetivo, estratégia de obtenção dos dados e a abordagem do problema (COLLIS; HUSSEY, 2005). Considerando o exposto, esta pesquisa pode ser classificada como descritiva em relação ao seu objetivo, survey em relação à coleta de dados, e qualiquantitativa em relação à abordagem de análise. Quanto ao método de abordagem do presente estudo, caracteriza-se como uma pesquisa com método indutivo, pois parte de 
um âmbito menor para uma indução a um resultado para demais organizações. Marconi e Lakatos (2009) corroboram mencionando que o método indutivo é aquele em que a aproximação dos fenômenos geralmente é elevada a extensões cada vez mais abrangentes, formando uma conexão ascendente.

Esta pesquisa classifica-se como descritiva em relação ao seu objetivo, pois visa a descrever e evidenciar a relevância das cooperativas de crédito para o desenvolvimento socioeconômico no contexto do município de Concórdia, no Estado de Santa Catarina. A pesquisa descritiva é aquela em que são feitos exames das relações entre as variáveis, com a coleta de seus dados em um único período e resumidos (CERVO; BERVIAN, 2002; SIMÕES; PEREIRA, 2009). Segundo Pereira (2012), a pesquisa descritiva observa e descreve determinado fenômeno ou população.

A estratégia de levantamento, conhecida como survey, foi adotada para a coleta de dados, uma vez que fora utilizado um questionário para coleta de dados. Para Freitas et al. (2000), uma pesquisa survey pode ser descrita como a aquisição de dados ou informações sobre características, ações ou opiniões de um determinado grupo de pessoas, fazendo o levantamento por meio de um questionário.

Além disso, o estudo é classificado como qualiquantitativo, pois os dados obtidos foram analisados mediante estatística descritiva, quanto aos dados objetivos, e por meio da análise qualitativa em relação às respostas das questões abertas do questionário. A obtenção de dados qualitativos e quantitativos permitiu a realização de triangulação entre ambos.

Para a coleta de dados utilizou-se a técnica de pesquisa de campo com a aplicação de questionário, o qual continha 14 perguntas e foi aplicado aos gerentes, diretores ou presidentes das cooperativas de crédito. $O$ instrumento utilizado apresentava 10 questões abertas, divididas em três blocos (apêndice A). No primeiro bloco foi verificado o início das atividades e dificuldades encontradas. No segundo, foram averiguados os setores de atuação e número de sócios por décadas da cooperativa. Já no terceiro e último bloco foram identificados os benefícios propostos aos seus colaboradores e demais contribuições para a sociedade local.

\section{Breve Descrição do Município}

O processo de colonização do município de Concórdia-SC ocorreu a partir do início (1920) do século passado, por descendentes italianos e alemães, principalmente, provenientes do Estado do Rio Grande do Sul (MARCHESAN, 2003).

A superfície territorial do município é de $797,26 \mathrm{~km}^{2}$. Sua população é de 73.742 habitantes (IBGE, 2018), com aproximadamente $80 \%$ de indivíduos residindo no meio urbano e $20 \%$ no meio rural. A densidade demográfica média atual é de aproximadamente 91,2 hab. $/ \mathrm{km}^{2}$.

O município de Concórdia destaca-se na economia catarinense. A atividade econômica principal é a agropecuária, com destaque para a suinocultura, avicultura e bovinocultura de leite. O referido município é sede da Cooperativa de Produção e Consumo Concórdia Ltda. (Copérdia), uma das maiores produtoras de proteína animal da região. Além dessa Cooperativa, há mais outras 30 que atuam no município, mostrando a expressividade com relação ao cooperativismo (MARCHESAN et al., 2019). Entre ou- 
Figura 1 - Mapa do Brasil, destacando Santa Catarina e Concórdia-SC

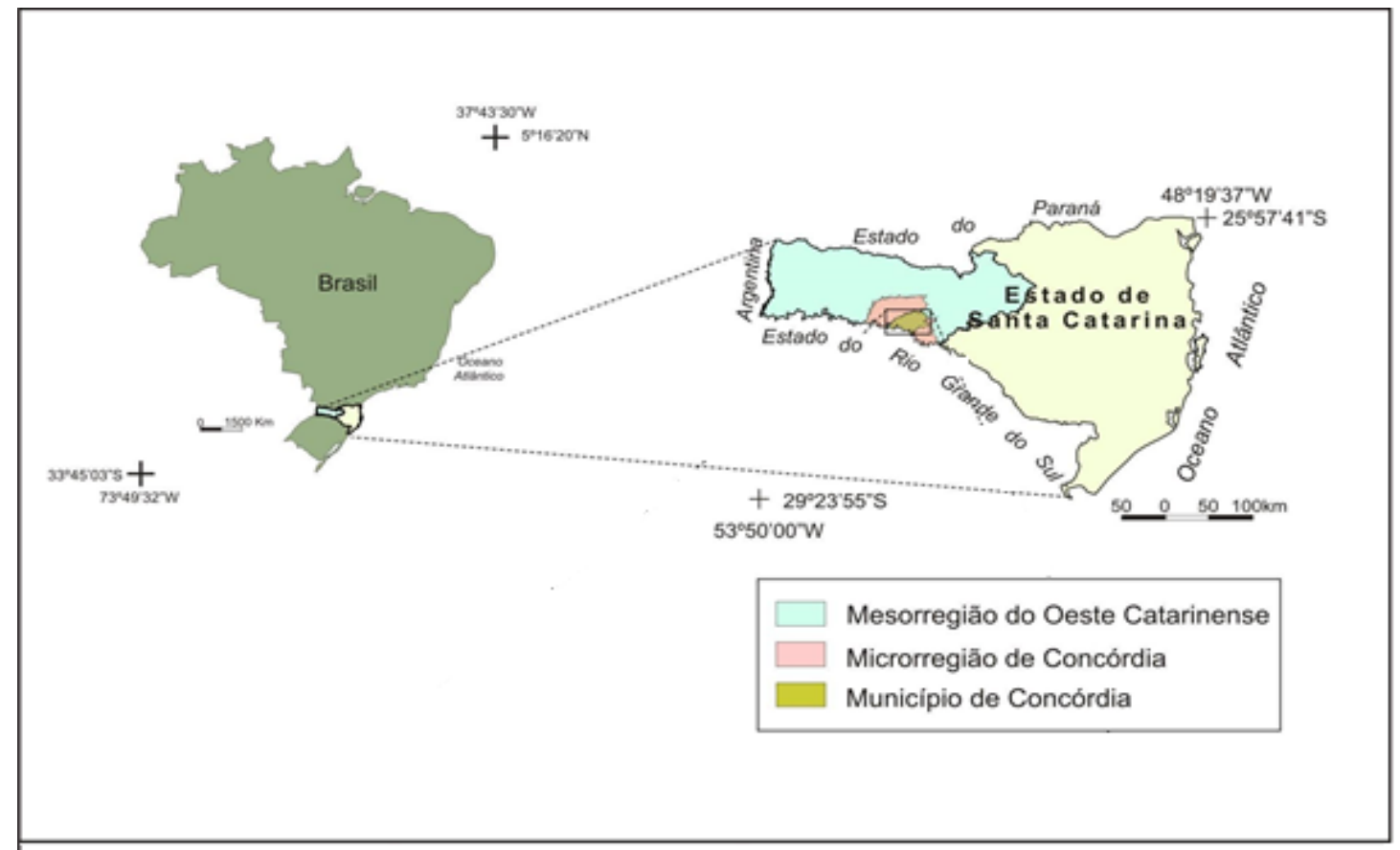

Fonte: Adaptado de IBGE (2018).

tras atividades econômicas, destacam-se o transporte de cargas, indústria moveleira, gráfica, alimentos, produção de software, cooperativismo em várias áreas, entre outras (GONÇALVES; VEGRO, 1994; TEDESCO et al., 2014). Existem ainda várias agroindústrias familiares que envolvem os pequenos agricultores e contribuem significativamente para a economia regional.

Já o cooperativismo de crédito no município conta com seis instituições de crédito: Cooperativa de Crédito do Alto Uruguai Catarinense (Sicoob Crediauc); Cooperativa de Economia e Crédito Mútuo dos Trabalhadores em Transportes Rodoviários de Concórdia e Região (Sicoob Transcredi); Sistema das Cooperativas de Crédito Rural com Interação Solidária (Cresol); Cooperativa de Crédito Unicred Desbravadora Ltda. - Unicred Desbravadora Sul (Unicred); Sistema de Crédito Cooperativo (Sicredi) e a Cooperativa de Crédito Uniprime, todas consolidadas nas dimensões política, econômica e social.

Na economia urbana destaca-se a atuação do setor comercial e de prestação de serviços e outros. Nesta direção, talvez seja possível afirmar que o cooperativismo em Concórdia, ao longo de décadas, ajuda a explicar a condição de destaque e de qualidade de vida, demonstrados pelos índices de desenvolvimento humano, social e econômico alcançados pelo município, quando comparado com outros com características semeIhantes, por exemplo, sob o ponto de vista demográfico, produtivo, entre outros.

O Índice de Desenvolvimento Humano (IDH) do município é de 0,849. No dia 28/6/18 foi divulgado pela Federação das Indústrias do Estado do Rio de Janeiro (Firjan) o Índice de Desenvolvimento Municipal. O município de Concórdia aparece em oitavo lugar no país e em primeiro no Estado de Santa Catarina (FIRJAN, 2016). 


\section{RESULTADOS E DISCUSSÃO}

Uma cooperativa de crédito consiste em uma associação de indivíduos com objetivo de efetuar negócios de forma simplificada, buscar crédito com juros mais acessíveis e executar suas movimentações financeiras em geral. De igual modo, uma cooperativa de crédito oferece tudo o que um "banco" tradicional disponibiliza aos seus clientes, no entanto as cooperativas têm o diferencial de realizar atendimento mais próximo do cooperado.

Outro fator positivo é que a cooperativa cobra de seu associado um valor destinado ao capital da instituição, que é alimentado ao final dos exercícios anuais com as sobras do ano anterior, destacando-se que este valor fica disponível para que o sócio o retire quando optar por deixar a cooperativa. Tendo em vista que uma cooperativa não tem fins lucrativos, explica-se assim o motivo pelo qual possui taxas de juros inferiores em seus empréstimos, quando comparadas aos bancos tradicionais (BÚRIGO et al., 2006).

Nas cooperativas de crédito os associados encontram os principais serviços disponíveis nos bancos, como conta corrente, aplicações financeiras, cartão de crédito, empréstimos e financiamentos. Os associados têm poder igual de voto, independentemente da sua cota de participação no capital social da cooperativa. O cooperativismo não visa lucros, os direitos e deveres de todos são iguais e a adesão é livre e voluntária (SICOOB, 2019) .

De acordo com a pesquisa de campo e com os relatos de presidentes e gerentes das cooperativas visitadas na presente pesquisa, as principais dificuldades para constituir e manter as cooperativas de crédito estão centradas nos seguintes pontos: (i) Disponibilidade de profissionais qualificados e experientes na área; (ii) Abordagem de novos cooperados, com comprovação da qualidade dos produtos e serviços prestados pela cooperativa; (iii) Concorrência com instituições bancárias consolidadas e que estão há mais tempo atuando no mercado financeiro. Foi relatado por um dos entrevistados que: "as dificuldades, muitas vezes, possibilitam a busca de soluções. Foi assim que as cooperativas de crédito atuaram para se consolidar e se fazerem presentes no mercado financeiro local". Esse achado é coerente com o apontado por Bretos e Marcuello (2016), que afirmam que as cooperativas necessitam adotar estratégias múltiplas, para que possam superar os desafios e se desenvolverem com sucesso em um ambiente global e competitivo. Em um cenário de desafios para as cooperativas, Buwah e Joyvice (2019) observam que a existência de políticas de governança estruturadas e abrangentes podem ser o alicerce para superação de desafios gerenciais dessas entidades.

Conforme o gráfico apresentado na Figura 2, é notório o crescimento no número de cooperados das cooperativas de crédito no município de Concórdia-SC. A origem está no ano de 1984, quando a primeira cooperativa de crédito - Sicoob/Crediauc - foi fundada no município. 
Figura 2 - Evolução do número de cooperados no município de Concórdia-SC

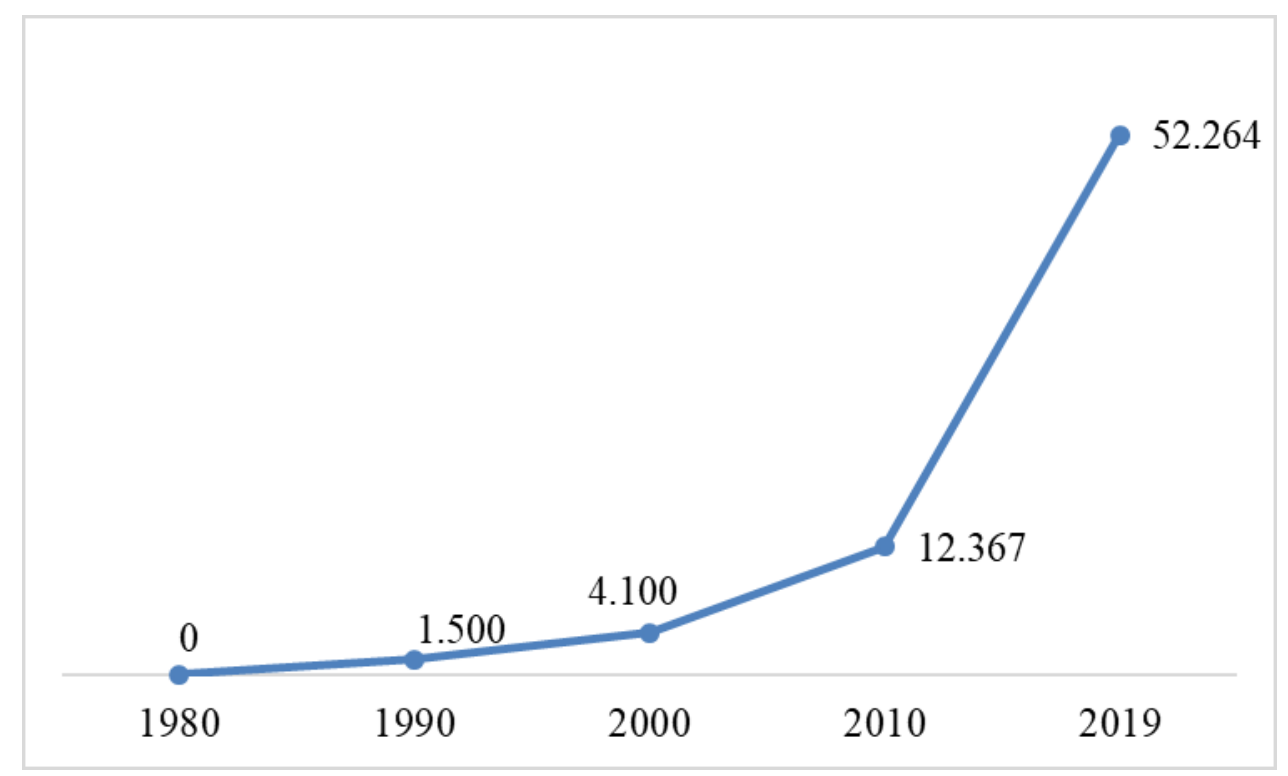

Fonte: Dados da pesquisa de campo (2019).

Diante dos dados apresentados, verifica-se aumento acentuado do setor cooperativista de crédito local. Isso é confirmado na Figura 2, em que se observa que no ano de 1984, ano da fundação da primeira cooperativa de crédito - Sicoob Crediauc - havia 33 associados. Já no ano de 2019 o município de Concórdia contava com mais de 52 mil associados. Esse dado mostra que aproximadamente $50 \%$ da população do município é associada em alguma cooperativa de crédito. Além disso, demonstra o expressivo crescimento do setor. Isso revela que os cooperados depositam confiança na cooperativa. Possivelmente, tal crédito e confiança foram sendo difundidos socialmente e a cooperativa foi conquistando espaços no seu setor de atuação.

Além disso, é importante observar ainda na Figura 2, que, desde a constituição da primeira cooperativa de crédito, na década de 80 , e ao longo de sua história de atuação local e regional, sempre houve crescimento anual do número de cooperados. É notório, no entanto, que a partir dos anos 2010, o crescimento foi mais acentuado. Nesse período mudanças em diretrizes, normas e legislações relacionadas às cooperativas de crédito também foram propulsoras para a expansão das cooperativas de crédito (JACQUES; GONÇALVES, 2016), principalmente no interior. Além disso, esse processo pode ser justificado a partir de algumas hipóteses relacionadas a aspectos culturais, ou seja: concepções, princípios e práticas sociais da população regional pelo associativismo e o cooperativismo; crescente confiança dos cooperados em suas cooperativas e, a partir disso, da divulgação positiva dos associados na comunidade; elaboração de estratégias por parte das cooperativas de crédito visando à busca de espaços no mercado e expansão de negócios, entrando com mais efetividade no mercado local, e utilização de sistemas qualificados de atendimento.

A partir da pesquisa qualitativa desenvolvida entende-se que os indivíduos procuram associar-se a cooperativas de crédito em busca de auxílio financeiro, possibilitando, a partir daí, movimentar a economia do município e, consequentemente, impulsionar o desenvolvimento socioeconômico. 
Todas as cooperativas descritas são filiadas à Organizações Cooperativas do Brasil (OCB), com exceção da Cooperativa Cresol, filiada à União Nacional da Cooperativas da Agricultura Familiar e Economia Solidária (Unicafes), a qual busca focar seus esforços em três principais setores: empresarial, pessoa física urbana e agronegócio. Na Tabela 1 evidenciam-se dados sobre o ano de fundação e o comparativo entre o número de associados iniciais e no ano de 2019.

Tabela 1 - Dados das Cooperativas de Crédito de Concórdia-SC

\begin{tabular}{c|ccc}
\hline Cooperativa & Ano da fundação & $\begin{array}{c}\text { No sócios } \\
\text { (ano fundação) }\end{array}$ & $\begin{array}{c}\text { No sócios } \\
\text { (2019) }\end{array}$ \\
\hline Sicoob Crediauc & 1984 & 33 & 20.002 \\
Sicoob Transcredi & 2002 & 102 & 22.507 \\
Unicred & 2000 & 40 & 690 \\
Cresol & 2002 & 44 & 4.286 \\
Sicredi & 2009 & 105 & 4.779 \\
\hline
\end{tabular}

Fonte: Dados da pesquisa (2019).

Em uma das cooperativas de crédito - Crediauc - o setor de agronegócio é o "carro-chefe" das operações de crédito; são os investimentos provenientes de recursos do governo federal por meio do Banco Nacional de Desenvolvimento Econômico e Social (BNDES). Neste sentido, a cooperativa acessa os recursos no BNDES e opera como intermediadora com seus cooperados. Dessa forma, o setor da agricultura é o maior beneficiado em relação a taxas de juros. Isto se justifica pelo fato de o Brasil ser um país dependente da produção agrícola em geral. Desta forma, o governo busca auxiliar os produtores para que consigam ter sequência nas suas atividades durante o ano. Nessa perspectiva, o município, assim como toda a região do Alto Uruguai Catarinense, onde atuam as cooperativas de crédito, predominam atividades agropecuárias, que são uma das bases da economia regional. Fernandes et al. (2018) identificaram em seu estudo que as cooperativas de crédito são agentes financeiros que contribuem para o desenvolvimento da agricultura familiar e, consequentemente, sustentável da economia local. Para os autores, é coerente que as cooperativas tenham maior atuação nas principais atividades econômicas da região em que estão inseridas.

O setor empresarial busca, além de recursos para investimentos, auxílio para capital de giro de suas empresas, usufruindo de taxas de juros mais acessíveis, disponibilizadas pelas cooperativas de crédito, diferentemente dos bancos tradicionais que se encontram instalados no município (SEBRAE, 2019). Assim sendo, o desenvolvimento comercial e industrial do município de Concórdia também passa pela atuação das cooperativas de crédito. Isso revela a importância do setor para o desenvolvimento socioeconômico do referido município.

Já no setor de pessoa física urbana são identificadas operações financeiras de menor escala, geralmente para aquisição de veículos, por exemplo, motos e carros e outros bens (duráveis e não duráveis), bem como para compra de terrenos, reformas e construções de casas.

A Figura 3 mostra a evolução do número de funcionários do setor de cooperativismo de crédito no município de Concórdia. 
Figura 3 - Números de funcionários atuantes nas cooperativas de crédito no município de Concórdia-SC

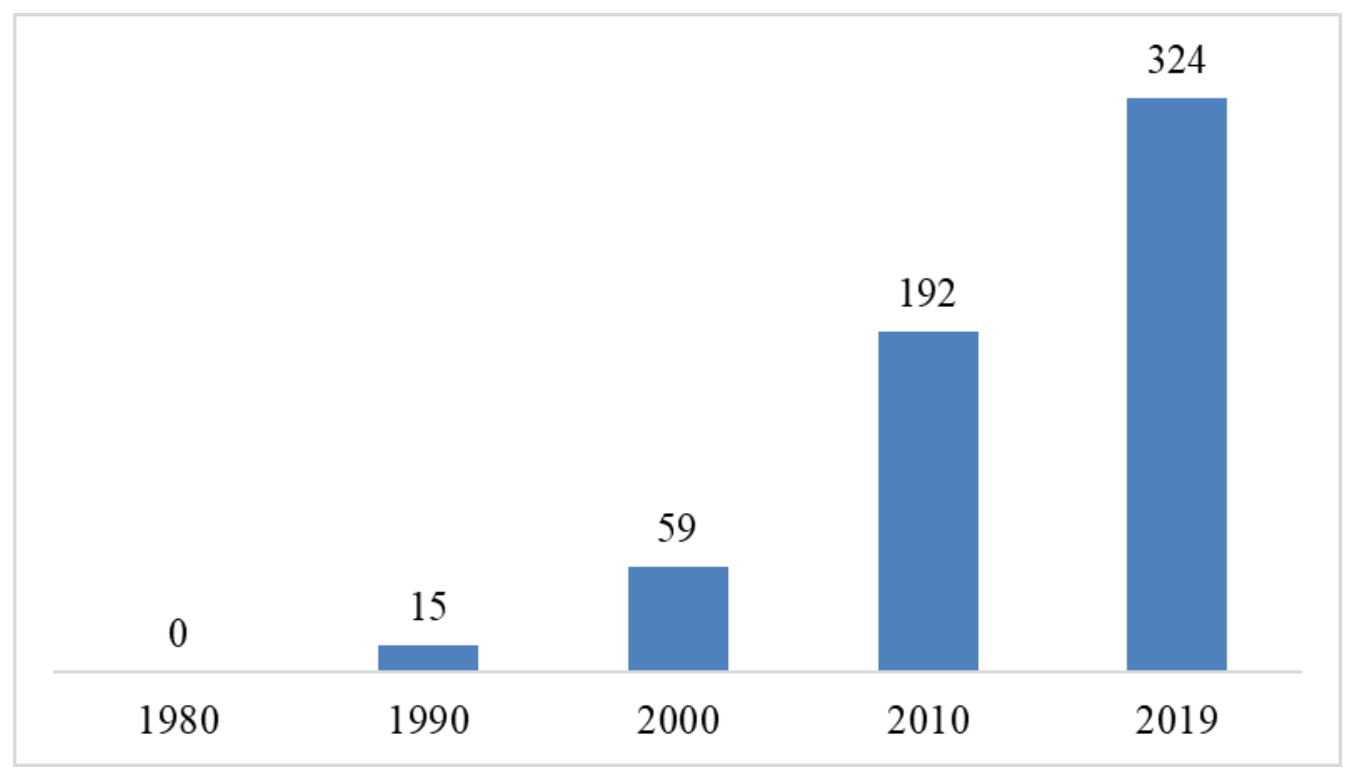

Fonte: Dados da pesquisa de campo (2019).

Observa-se o aumento da geração de empregos e de renda direta para os indivíduos do município, uma vez que são mais de 300 pessoas atuando nas cooperativas de crédito local e regional.

Além disso, há de se ressalvar, a partir da pesquisa de campo, que as cooperativas proporcionam aos seus funcionários e cooperados cursos e treinamentos internos e externos, preparando-os cada vez mais para atuarem no mercado financeiro e aprimorando-os para o atendimento aos cooperados e interessados em negócios. Conforme previsto na Lei 5.764/71, as cooperativas devem constituir o Fundo de Assistência Técnica, Educacional e Social (Fates), o qual tem por objetivo ser um recurso destinado para assistência aos associados e seus familiares e também para formação dos colaboradores. Esse achado é corroborado pelos resultados do estudo de Lima, Oliveira e Colombelli (2018), que identificaram que em cidades onde há cooperativas o índice de desenvolvimento humano é de até $0,1 \%$. Para os autores, esse é o reflexo dos investimentos que as cooperativas realizam para o desenvolvimento das pessoas, sendo elas cooperadas ou associadas.

As cooperativas também incentivam seus funcionários de forma monetária, disponibilizando a possibilidade de qualificação profissional e, principalmente acadêmica, por meio do pagamento de porcentagens que variam de $30 \%$ a $80 \%$ das mensalidades para cursos superiores, de acordo com o tempo de emprego na cooperativa. Isso vale para níveis de Graduação, Pós-Graduação, MBA, Mestrado e Doutorado.

Os projetos sociais também estão intrínsecos e fazem parte dos propósitos cooperativistas. Por isso, as cooperativas de crédito do município auxiliam financeiramente as Organizações Não Governamentais (ONGs), as populações de comunidades carentes que possuem crianças e adolescentes em estado de vulnerabilidade social ou com necessidades especiais, mediante investimentos em formação humana e social por meio de projetos. Afinal, as cooperativas possuem porcentagens de suas sobras anuais reservadas para estes fins e asseguradas por aprovações em suas assembleias. 
A título de exemplo, a Cooperativa Sicoob Crediauc disponibiliza 0,5\% das sobras anuais para projetos sociais, entre os quais destacam-se: Projeto Sesi Ciências - Eletricidade se Liga aí, Dia do Desafio; "Lixo Zero" - recolhimento de lixo eletrônico, piIhas, lâmpadas e vidros, em parceria com a Fundação Municipal do Meio Ambiente de Concórdia (Fundema), Projeto Filó, de apoio para valorização da cultura italiana, entre outros.

Nessa mesma perspectiva, a Cooperativa Cresol também desempenha seu papel social com atividades esportivas, apoio a entidades como Corpo de Bombeiros Voluntários, Associação de Pais e Amigos dos Excepcionais (Apae), entre outros. Seguindo esta linha, a Sicredi, o Sicoob Transcredi e a Unicred também auxiliam em campanhas do agasalho, apoio e patrocínio em cursos e palestras educativas para as comunidades e ações de caridade em datas comemorativas.

De maneira geral, a presença mais intensa na comunidade, bem como este conjunto de ações, investimentos e projetos desenvolvidos e executados pelas cooperativas de crédito na sociedade são significativos para melhorias regionais e para novas possibilidades de desenvolvimento socioeconômico. Esse fato pode ser uma das justificativas para a crescente expansão do cooperativismo de crédito regional. Para Bretos e Marcuello (2016), o impacto das cooperativas no desenvolvimento regional de onde estão inseridas pode se dar por meio da utilização de múltiplas estratégias, sendo possível ponderar que as cooperativas de crédito na cidade de Concórdia não causam impacto apenas por meio dos seus serviços financeiros, mas também mediante ações estratégicas realizadas junto a diferentes entidades sociais e instituições da comunidade.

Por fim, os resultados encontrados neste estudo são coerentes com os já encontrados em Bretos e Marcuello (2016); Nan, Gao e Zhou (2019); Fernandes et al. (2018); Lima, Oliveira e Colombelli (2018) e Caporale et al. (2016), e que auxiliam na sustentação para que as contribuições das cooperativas de crédito para o desenvolvimento local possam ser classificadas em quatro categorias, como: (i) ações sociais, nas quais estão as atividades realizadas em prol e em conjunto com organizações sociais, (ii) formação de capital humano, em que estão os incentivos e contribuições da cooperativa para a formação de seus colaboradores e cooperados por meio de programas específicos, (iii) empreendedorismo, por meio dos seus serviços financeiros especializados e destinados às entidades empresariais com linhas de crédito para fomento da economia, geração de emprego e desenvolvimento do agronegócio, e, por fim, (iv) finanças pessoais, envolvendo as ações para o fortalecimento da educação financeira da sociedade, colaboradores e cooperados.

\section{CONSIDERAÇÕES FINAIS}

O presente estudo teve por objetivo analisar a evolução do setor de cooperativismo de crédito no município de Concórdia-SC e suas contribuições para o desenvolvimento socioeconômico do município. Nessa perspectiva, identificou-se que o cooperativismo de crédito está atuando com intensidade no mercado financeiro regional, com bases sólidas e objetivos definidos.

É notório o crescimento do sistema cooperativista de crédito no município, o qual acompanha a tendência nacional e é sustentado por cooperados que buscam nesse meio novas formas de fazer negócios, novos produtos e serviços que são oferecidos, 
com taxas de juros atrativas e favoráveis para que possam gerir suas propriedades rurais, empresas ou até mesmo sua vida pessoal, além de colaborar com o desenvolvimento socioeconômico da região em que atuam.

Além dos números apresentados nesta pesquisa, os quais mostram o crescimento do setor cooperativista de crédito, observa-se ou constata-se no município de Concórdia-SC e também na microrregião da Associação dos Municípios do Alto Uruguai Catarinense (Amauc) a crescente presença e atuação do setor. Dessa forma, se há crescimento do cooperativismo de crédito, possivelmente há redução dos negócios nas agências privadas ou públicas.

Neste cenário, entre as vantagens do cooperativismo de crédito é que os lucros dos negócios são distribuídos entre os sócios e tendem a ser reinvestidos no município ou na região. O contrário também pode ser verdadeiro. Ou seja, os lucros dos negócios das agências de crédito públicas ou privadas podem ser ou são retirados do município ou da região e destinados para fora ou para os centros nacionais ou internacionais, onde estão localizadas as sedes das referidas agências. Se os recursos financeiros são distribuídos para os cooperados, ficam ou tendem a ficar no município e na região, logo, constata-se que há maior movimento econômico local e regional, contribuindo para a geração de novos negócios, trabalho, renda e desenvolvimento socioeconômico.

Uma pesquisa como esta, primeiramente, contribui e incentiva a iniciação científica. Paralelamente, colabora teoricamente com o avanço da ciência na área do cooperativismo de crédito. De igual modo, fornece informações a respeito do setor cooperativista local e regional, bem como mostra o crescimento do referido setor na e para a sociedade.

É oportuno destacar e reconhecer, também, as limitações deste estudo. Afinal, o crescimento intelectual é um processo que exige sempre mais leituras, análises, interpretações e pesquisas. Por isso, novos estudos sobre este objeto - cooperativismo de crédito - poderão e deverão ser ampliados e potencializados na perspectiva de contribuir cientificamente e também socialmente.

Por fim, conclui-se que o sistema cooperativista de crédito está contribuindo significativamente na geração de trabalho, distribuição de renda, e, consequentemente, com o desenvolvimento local e regional.

\section{REFERÊNCIAS}

ANTONIALLI, L. M. Influência da mudança de gestão nas estratégias de uma cooperativa agropecuária. Revista de Administração Contemporânea, v. 4, n. 1, p. 135-159, 2011.

ANUÁRIO DO COOPERATIVISMO BRASILEIRO. Sistema Organização das Cooperativas Brasileiras (OCB). 2019. Disponível em: http://www.paranacooperativo.coop.br/ppc/ima ges/Comunicacao/2019/noticias/07/04/publicacao/publicacao_clique_aqui_04_07_2019.pdf. Acesso em: 28 jan. 2020.

BRESSAN, V. G. F. et al. Uma proposta de indicadores contábeis aplicados às cooperativas de crédito brasileiras. Revista de Contabilidade e Controladoria, v. 2, n. 4, p. 58-80, 2010.

BRETOS, I.; MARCUELLO, C. Revisiting globalization challengens and opportunities in the devolopment of cooperatives. Annals of Public and Cooperative Economics, v. 88, n. 1, p. 47-73, 2016.

BÚRIGO, F. L. et al. Finanças e solidariedade: uma análise do cooperativismo de crédito rural solidário no Brasil. Estud. Soc. Agric., Rio de Janeiro, v. 14, n. 2, 2006.

BUWAH, N. N.; JOYVICE, C. An analysis of managerial challenges of affiliated credit unions to Cameroon cooperative credit union league (CamCCUL). Journal of Scientific Research and Reports, v. 22 , n. 3, p. 1-8, 2019. 
CANÇADO, A. C. Cooperativismo. In: BOULLOSA, Rosana de Freitas (org.). Dicionário para a formação em gestão social. Salvador: Ciags; Ufba, 2014. p. 39-41.

CAPORALE, G. M. et al. Local banking and local economic growth in Italy: some panel evidence. Journal Applied Economics, v. 48, n. 28, p. 2.665-2.674, 2016.

CERVO, A. L.; BERVIAN, P. A. Metodologia científica. [S.I: s.n.], 2002. V. 5.

COCCORESE, P.; SHAFFER, S. Cooperative Banks and Local Economic Growth. Cama Working Paper, n. 11/2018. Disponível em: http://dx.doi.org/10.2 139/ssrn.3125909.

COLLIS, J.; HUSSEY, R. Pesquisa em administração: um guia prático para alunos de graduação e pós-graduação. 2. ed. Porto Alegre: Bookmann, 2005.

FERREIRA, M. A. M.; GONÇALVES, R. M. L.; BRAGA, M. J. Investigação do desempenho das cooperativas de crédito de Minas Gerais por meio da Análise Envoltória de Dados (DEA). Econ. Aplic, v. 11, p. 425-445, 2007.

FERNANDES, R. A. et al. Contribuição das cooperativas de crédito no desenvolvimento da agricultura familiar: o caso da Sulcredi Ouro. Revista Desenvolvimento Socioeconômico em Debate - RDSD, v. 4, n. 1, p. 88-105, 2018.

FIRJAN. Índice Firjan de Desenvolvimento Municipal. Disponível em: https://www.firjan.com.br/ifdm/ consulta-ao-indice/ifdm-indice-firjan-de-desenvolvimento-municipal-resultado.htm?UF=SC\&IdCidade $=420430 \&$ Indicador $=1 \&$ Ano $=2016$.

FREITAS, H. et al. O método de pesquisa survey. Revista de Administração, São Paulo, v. 35, n. 3, p. 105112, jul./set. 2000.

GONÇALVES, J. S.; VEGRO, C. L. R. Crise econômica e cooperativismo agrícola: uma discussão sobre os condicionantes das dificuldades financeiras da Cooperativa Agrícola de Cotia (CAC). Agricultura em São Paulo, v. 41, n. 2, p. 57-87, 1994.

IBGE. Instituto Brasileiro de Geografia e Estatística. Dados municipais. 2018. Disponível em: https://cidades.ibge .gov.br/brasil/sc/concordia. Acesso em: 3 fev. 2019.

JACQUES, E. R.; GONÇALVES, F. O. Cooperativas de crédito no Brasil: evolução e impacto sobre a renda dos municípios brasileiros. Economia e Sociedade, v. 25, n. 2(57), p. 489-509, 2016.

LIMA, A. V.; OLIVEIRA, C. F.; COLOMBELLI, G. L. O papel das cooperativas no desenvolvimento regional. Revista da Mostra de Iniciação Científica, v. 4, n. 1, 2018.

MARCHESAN, J. A questão ambiental na produção agrícola: um estudo sócio-histórico-cultural no município de Concórdia (SC). ljuí: Editora Unijuí, 2003.

MARCHESAN, J. et al. Crescimento e contribuições do setor cooperativista no município de Concórdia, Santa Catarina. In: Revista Húmus, v. 9, n. 27, 2019.

MARCHESAN, J.; BONETI, L. W.; TOMPOROSKI, A. A. Cooperativismo como princípio humano. Revista Profanações, v. 6, num. esp., p. 212-226, nov. 2019.

MARCONI, M. A.; LAKATOS, E. M. Metodologia do trabalho científico: procedimentos básicos, pesquisa bibliográfica, projeto e relatório, publicações e trabalhos científicos. 7. ed. São Paulo: Atlas, 2009.

MENEZES, C. M.; LAJUS, M. L. DE S. Cooperativismo de crédito e desenvolvimento. Revista Economia e Desenvolvimento, v. 14, n. 2, p. 294-313, 2015.

MCKILLOP, D. et al. Cooperative financial institutions: a review of the literature. Woriking Paper in Responsible Banking \& Finance, University of St Andrews - School of Management, WP no 20-005, 2020.

NAN, Y.; GAO, Y.; ZHOU, Q. Rural credit cooperatives' contribution to agricultural growth: evidence from China. Agricultural Finance Review, v. 79, n. 1, p. 119-135, 2019.

NOVKOVIC, S. Defining the co-operatives difference. The Journal of Socio-Economics, v. 37, n. 6, p. 2.1682.177, 2008.

OCESC. Organização das Cooperativas do Estado de Santa Catarina; SESCOOP/SC. Serviço Nacional de Aprendizagem do Cooperativismo. O cooperativismo ao alcance de todos. 19. ed. Florianópolis: Gráfica Rocha, 2018.

PEREIRA, M. Manual de metodologia da pesquisa científica. 3. ed. São Paulo: Atlas, 2012. (VitalBook file). PORTO, S. B.; FERREIRA, M. V. Cooperativismo e desenvolvimento socioeconômico: uma análise da Cooperativa de Crédito Rural de Economia Solidária Solicred Benjamin Constant/AM. Cadernos Gestão Social, v. 5, n. 2, p. 323-337, 2014.

RISSON, C. Boas práticas cooperativas. In: MAGRI, Cledir A. et al. Cooperativismo de crédito solidário: reflexões e boas práticas. Passo Fundo: Editora Ifibe, 2010. 
SAMIAN, M. et al. The role of fishing cooperatives on social-economic and cultural development of rural areas of Bord Khun city of Bushehr, Iran. Journal of the Saudi Society of Agricultural Sciences, v. 16, n. 2, p. 178-183, 2017.

SEBRAE. Serviço Brasileiro de Apoio às Micro e Pequenas Empresas. Capital de giro: aprenda o que é e como funciona o da sua empresa. Disponível em: http://www.sebrae.com.br/sites/PortalSebrae/artigos/o-que-e-e-como-funciona-o-capital-de-giro,a4c8e8da69133410VgnVCM1000003b74010aRCRD. Acesso em: 24 abr. 2019.

SESCOOP. Serviço Nacional de Aprendizagem do Cooperativismo. Fundamentos do Cooperativismo. Brasília, DF: SESCOOP, 2017.

SICOOB. Sistema de Cooperativas de Crédito do Brasil. Cooperativa de crédito. 2019. Disponível em: http://www.sicoobs c.com.br/sicoob-sc/cooperativismo/cooperativa-de-credito/.

SILVA, T. P. da; HEIN, N. Limite do risco positivo ao crescimento das atividades de crédito de cooperativas de crédito. Revista Globalização, Competitividade e Governabilidade, v. 6, n. 3, p. 50-69, 2012.

SIMÕES, S.; PEREIRA, M. A. M. A arte e a ciência de fazer perguntas: aspectos cognitivos da metodologia de survey e a contrução do questionário. [S.I: s.n.], 2009.

TEDESCO, G. M. I. et al. Mercado de Transporte Rodoviário de Cargas no Brasil. Revista Antt, p. 1-9, 2014.

VILELA, D. L.; NAGANO, M. S.; MERLO, E. M. Aplicação da análise envoltória de dados em cooperativas de crédito rural. Revista de Administração Contemporânea, v. 11, n. spe. 2, p. 99-120, 2008.

ZORDAN, M. A. Cooperativismo: ideias e posições. Chapecó: Arcus Indústria Gráfica, 2016.

WILDNER, M. C.; OLIVEIRA, S. V.; MARTINELLI JUNIOR, O. As ações das cooperativas agrícolas frente à cadeia produtiva do biodiesel no Rio Grande do Sul: evidências em direção ao desenvolvimento regional. Extensão Rural, v. 25, n. 2, p. 92-111, 2018. 


\section{APÊNDICE A}

Questionário para gerentes, diretores ou presidentes das cooperativas de crédito Acadêmico: Bruno Pilatti Rovani

Curso: Ciências Contábeis

Instituição: Universidade do Contestado (UnC) - Campus Concórdia-SC

\section{Identificação:}

\section{Função:}

\section{Cooperativa de crédito:}

\section{Bloco}

1. Ano da fundação da Cooperativa

2. Número de sócios no ano da fundação:

3. Dificuldades no início da Cooperativa

\section{Bloco}

4. Quais os setores de atuação - em ordem crescente

5. Qual é o maior público sócio da Cooperativa?

6. Número de sócios por década

7. Número de funcionários por décadas

8. Filiada à Organização das Cooperativas Brasileiras (OCB)

9. A Cooperativa atua em outros Estados?

( ) Sim. Se, sim, em qual ou quais?

( ) Não

\section{3으 Bloco}

10. A Cooperativa contribui financeiramente nos estudos dos seus funcionários?

( ) Sim. Se, sim, quanto? Se, sim, até quais níveis?

( ) Não

11. Quais as principais ações sociais (em ordem crescente) que a Cooperativa contribuiu ou está envolvida?

12. A Cooperativa contribui em ações sociais?

13. Quais as principais dificuldades (limites) (em ordem crescente) na atuação da Cooperativa?

14. Como as Cooperativas de crédito contribuem para ou na sua região de atuação?

15. Qual a participação das Cooperativas no mercado financeiro local? 